\title{
Evaluation of immunogenicity and protective activity in BALB/c mice of the 25-kDa major outer-membrane protein of Brucella melitensis (Omp25) expressed in Escherichia coli
}

\author{
R. A. BOWDEN, A. CLOECKAERT, M. S. ZYGMUNT and G. DUBRAY
}

Laboratoire de Pathologie Infectieuse et Immunologie, Institut National de la Recherche Agronomique, 37380 Nouzilly, France

\begin{abstract}
The antibody response specific to the 25-kDa major outer-membrane protein (Omp25) of Brucella melitensis expressed in Escherichia coli was assessed in BALB/c mice. Groups of mice were immunised and boosted either with sonicated $E$. coli carrying plasmid pAC2533 - $E$. coli (pAC2533) - expressing the gene coding for Omp25 (omp25 gene) of $B$. melitensis, or with $E$. coli carrying plasmid pUC19 - E. coli (pUC19). One control group received saline. The evolution of antibody responses was investigated by indirect ELISA with whole rough $(\mathrm{R})$ B. melitensis $\mathbf{H} 38$ cells as antigen. Serum antibody titres of mice immunised with $E$. coli (pAC2533) were appreciably higher than those of mice immunised with $E$. coli (pUC19). The specificity to Omp25 of murine antibodies induced by $E$. coli (pAC2533) was demonstrated by SDS-PAGE and immunoblotting of five $B$. melitensis strains. Binding of antibody in $E$. coli (pAC2533) immune sera to the surface of $B$. melitensis strains differing in their smooth lipopolysaccharide (S-LPS) expression was also studied by whole-cell ELISA and by flow cytometry. Antibody reactivity to $R$ and smooth-rough (S-R) was much stronger than that to smooth (S) B. melitensis strains, indicating a much better accessibility of Omp25 to antibody on strains lacking or expressing less O-polysaccharide on their surface. The antibodies to Omp25 were predominantly of IgG2a isotype. The capacity of $E$. coli (pAC2533) to induce protective immune responses against four challenge strains of $B$. melitensis was further evaluated in mice. Significant reductions in splenic infections, in comparison with mice immunised with $E$. coli (pUC19) and unimmunised (saline injection) mice, were observed in R B. melitensis B115, S-R B. melitensis EP and S B. melitensis $\mathbf{H} 38$ infected mice. Protection against $S$. melitensis $16 \mathrm{M}$ was not significant. The data from the present study, together with previous results, suggest that humoral immunity against probably conformational, well-exposed epitopes of the Omp25 could contribute to protective mechanisms against $B$. melitensis infection in mice.
\end{abstract}

\section{Introduction}

The search for new vaccines against Brucella spp., overcoming the drawbacks of those currently used, is a goal for several laboratories worldwide [for reviews see refs 1 and 2]. They have directed efforts to the identification, characterisation and isolation of bacterial fractions capable of retaining protective activity. Several antigens that induce protective responses have been localised in the outer membrane of brucella cells

Received 22 April 1997; accepted 1 May 1997.

Corresponding author: Dr R. A. Bowden. Present address: Laboratorio de Inmunoquímica y Biotecnología, Facultad de Ciencias Veterinarias, UNICEN, 7000 Tandil, Argentina.

E-mail: rbowden@vet.unicen.edu.ar; Fax: +54 29326667.
[3-7]. Bacterial surface antigens are prime candidates for vaccines as they represent the initial point of contact between the pathogen and their host [8].

Two brucella fractions able to induce protection in mice under different experimental conditions contain major components of the outer membrane: the sodiumdodecyl-sulphate-insoluble (SDS-I) fraction [3-5, 7, 9, 10] and the hot-saline (HS) extract $[6,11]$. The SDS-I fraction contains smooth (S) and rough (R) lipopolysaccharides (LPS), depending on the strain used to obtain it, peptidoglycan (PG) and the major outermembrane proteins (OMPs) of $25-27 \mathrm{kDa}, 31-34 \mathrm{kDa}$ and $36-38 \mathrm{kDa}$ tightly bound to PG $[4,9,10,12]$. The major OMPs are also called group $3(25-30 \mathrm{kDa})$ and group $2(36-38 \mathrm{kDa})$ proteins, respectively $[10,13]$. 
Furthermore, HS extract, obtained from B. ovis was shown to contain mainly R-LPS and group 3 OMPs [11]. The protective activity of purified brucella $25-\mathrm{kDa}$ OMP [3] or the analogous group 3 OMP [7] has been studied in mouse models as a potential vaccine candidate. However, the evaluation of the importance of these proteins in protection has so far been hampered by the presence of brucella LPS in all these fractions, which is strongly associated with OMPs [5, 14, 15]. Moreover, the proteins used in the trials had been extracted from brucella cell envelopes by harsh, denaturing treatments. These problems were addressed by passive protection experiments in mice with OMPspecific monoclonal antibodies (MAbs). MAbs directed to at least three epitopes of the O-chain of brucella SLPS were protective in mice [16-20]. However, in similar experiments MAbs specific for OMPs and RLPS either failed to protect or conferred very limited protection against smooth Brucella strains [19, 21-23], most likely because of the shielding effect of the Ochains of S-LPS [21, 22, 24, 25]. As the use of MAbs which probably cover only a few specificities of the 25 $\mathrm{kDa}$ OMP could have led to underestimation of the protective activity of this molecule, active protection tests were reconsidered.

The 25-kDa OMP (Omp25) is a major OMP in $B$. melitensis $[9,25]$ among the proteins so far identified as being surface-exposed [24, 25]. The gene coding for Omp25 of B. abortus (omp25) was recently cloned and sequenced [26]. Polymerase chain reaction and restriction fragment length polymorphism analysis showed that the omp 25 gene is highly conserved among Brucella spp. and strains [27]. This was further confirmed by nucleotide sequence analysis of the omp 25 gene of the different Brucella spp. [28]. The omp 25 gene of each Brucella spp. was cloned and expressed in E. coli [28]. By use of anti-Omp25 MAbs it has been shown that Omp25 was expressed in the E. coli outer membrane [28]. Moreover, insertion of Omp25 in the $E$. coli outer membrane allowed the correct folding and preservation of potentially important conformational epitopes [28]. Thus, the construction enabled more precisely investigation of the role played by this major OMP in protective immunity.

This report describes the first results obtained in BALB/c mice on the immunogenicity of Omp25 of $B$. melitensis expressed at the surface of $E$. coli and an evaluation of its protection inducing activity against $B$. melitensis infection.

\section{Materials and methods}

\section{Bacteria and plasmids}

The Brucella strains, from the INRA Nouzilly Brucella culture collection, were S B. melitensis $53 \mathrm{H} 38, \mathrm{H} 38$ (S), currently used as the challenge strain in experi- mental infections, and its $\mathrm{R}$ variant, $\mathrm{H} 38(\mathrm{R}) ; \mathrm{S} B$. melitensis $16 \mathrm{M}$, the type strain of the genus Brucella and reference for biovar 1 of $B$. melitensis [29], $B$. melitensis EP, behaving as a S-R strain because of a small amount of surface S-LPS [30]; and B. melitensis B115, a R strain isolated from goat's milk in Malta (G.G. Alton, personal communication) which contains intracellularly expressed O-polysaccharide chain [31]. Plasmid pAC2533 containing the omp25 gene of $B$. melitensis $16 \mathrm{M}$ was constructed as described previously [28]. Expression of the omp 25 gene of $B$. melitensis was under the control of the Plac promoter. Cultures of E. coli (pAC2533) or E. coli (pUC19) (TG1 strains) were prepared as follows. Overnight cultures grown at $37^{\circ} \mathrm{C}$ were adjusted to an absorbance value $\left(A_{600}\right)$ of 0.1 in $50 \mathrm{ml}$ of Luria Bertani medium. After incubation for $2 \mathrm{~h}$ at $37^{\circ} \mathrm{C}$ with stirring, IPTG was added to a final concentration of $1.0 \mathrm{mM}$. Cultures were allowed to continue growth for $4 \mathrm{~h}$ at $37^{\circ} \mathrm{C}$ with stirring and were then harvested by centrifugation $(4000 \times g, 30 \mathrm{~min}$ at $4^{\circ} \mathrm{C}$ ). Pellets were suspended in phosphate-buffered saline (PBS) and prepared for inoculation. Expression of omp 25 was checked with MAbs by ELISA and immunoblotting [28].

\section{Monoclonal antibodies}

The generation and characteristics of MAbs have been described previously [25]. MAbs used were: A59/ 05F05/C09 (IgG2a), specific for Omp25; MAb A76/08C03/G03 (IgG2a), specific for the $16.5 \mathrm{kDa}$ OMP; and MAb A68/03F03/D05 (IgG2b) specific for R-LPS of Brucella. MAbs were used as ascitic fluids.

\section{Mice and immunisation}

Female, 5-6-week-old BALB/c mice (IFFA Credo, Orléans France) were randomised into groups of six and acclimatised for 1 week before starting immunisations. They received water and food ad libitum. Suspensions of E. coli (pAC2533) and E. coli (pUC19) cells were sonicated (amplitude 5, power setting: high; MSE $150 \mathrm{~W}$ Ultrasonic Disintegrator, Sussex) before injection. Animals were first inoculated intravenously (i.v.) either with $E$. coli (pAC2533) or $E$. coli (pUC19); $0.2 \mathrm{ml}$ of suspensions with an $\mathrm{A}_{600}$ value of 5.0 before sonication were used $\left(\mathrm{A}_{600}\right.$ of 10.0 corresponds to $c .10^{9}$ E. coli cells $/ \mathrm{ml}$ ). Fifty days later the mice were given booster injections intraperitoneally (i.p.) of the respective antigens $(0.2 \mathrm{ml}$ suspensions with $\mathrm{A}_{600}$ values of 0.5 before sonication). A third group of mice, inoculated with saline, served as control. Sera were obtained by retro-orbital bleeding under ether anaesthesia at 15,30, 45, 65 and 80 days after the first immunisation.

\section{ELISA}

The brucella suspensions used to coat plates were cells grown for $24 \mathrm{~h}$ on tryptose soy agar (TSA), harvested 
and heat-inactivated $\left(65^{\circ} \mathrm{C}, 60 \mathrm{~min}\right)$. Sterility was checked by subculture on TSA. For antibody determination, 96-well flat-bottomed plates (Greiner, Stuttgart, Germany) were coated overnight with $100 \mu \mathrm{l}$ of a suspension of E. coli (pAC2533) or E. coli (pUC19) (1 in 100 dilution of a suspension at an $A_{600}$ value of 0.5 ), or B. melitensis strains H38 (R), H38 (S), EP (S-R), $16 \mathrm{M}(\mathrm{S})$, or B115 (R) respectively (suspensions at an $\mathrm{A}_{600}$ value of 1.0 ) diluted in $0.1 \mathrm{M}$ sodium bicarbonate buffer, $\mathrm{pH}$ 9.6. The plates were washed five times with Tween $200.05 \%$ in $0.15 \mathrm{M} \mathrm{NaCl}$ between incubations. Three-fold serum dilutions ( 1 in 30 to 1 in 177147, in Tween $0.05 \%$ PBS) were distributed at $100 \mu 1$ per well and incubated for $2 \mathrm{~h}$ at $37^{\circ} \mathrm{C}$. Bound antibodies were detected by successive incubation with biotinylated sheep anti-mouse IgG immunoglobulins (Amersham, Aylesbury; 1 in 1000 dilution, $1 \mathrm{~h}$ at room temperature - $20-22^{\circ} \mathrm{C}$ ) and peroxidase-conjugated streptavidin (Amersham; 1 in 1000 dilution, $1 \mathrm{~h}$ at room temperature). Enzyme activity was revealed by adding $100 \mu \mathrm{l}$ of a solution containing $4 \mathrm{mM} \mathrm{H}_{2} \mathrm{O}_{2}$ and $1 \mathrm{mM} \mathrm{2}$, 2 '-azino-bis (3-ethylbenzothiazoline-6-sulphonic acid) (ABTS) and developing for $60 \mathrm{~min}$ at room temperature with continuous shaking. Colour was read at $414 \mathrm{~nm}$. Titres were calculated by interpolating in the linear response part of dilution curves at $\mathrm{A}=0.2$. Conditions were the same for isotype determination of the antibody, except that biotinylated sheep anti-mouse IgG1, IgG2a, IgG2b, IgG3 and IgM (Amersham; 1 in 1000 dilution) were used.

For binding determinations with anti-R-LPS MAb A68/03F03/D05 and anti-Omp25 MAb A59/5F05/ $\mathrm{C} 09, \mathrm{MAb}$ dilutions ( 1 in 30 to 1 in 177147) were distributed on plates coated under the same conditions as for serum antibody determination. After incubation for $2 \mathrm{~h}$ at $37^{\circ} \mathrm{C}$, bound $\mathrm{MAb}$ was detected with a peroxidase-conjugated goat anti-mouse $\operatorname{IgG}(\mathrm{H}+\mathrm{L})$ affinity purified serum (BioRad, Richmond) incubated for $1 \mathrm{~h}$ at room temperature. Enzyme activity and plate reading were carried out as above.

\section{Flow cytometry}

For flow cytometric analysis, $200 \mu 1$ of a suspension $\left(\mathrm{A}_{600}\right.$ value of 0.165$)$ of brucella cells (prepared as described for ELISA) were incubated $\left(1 \mathrm{~h}, 37^{\circ} \mathrm{C}\right)$ with pooled immune sera diluted 1 in 300 in $0.01 \mathrm{M}$ PBS, pH 7.2 , in Eppendorf polystyrene conical vials. After two washes with $0.5 \mathrm{ml}$ of PBS, bound serum antibodies were detected by incubating cells in $200 \mu \mathrm{l}$ of a 1 in 150 dilution of FITC-conjugated goat anti-mouse IgG $(\mathrm{H}+\mathrm{L})$ serum (Sigma), washed twice and resuspended to a volume of $0.5 \mathrm{ml}$. Suspensions were then gently sonicated for $5 \mathrm{~s}$ to disaggregate possible clumping due to repeated centrifugation and finally filtered through a fine nylon mesh. Negative controls were bacteria incubated only with the conjugate and these cells were used to set the acquisition parameters; 20000 brucella cells were analysed in each sample. Background and non-specific fluorescence signals were excluded from the analysis. Sample population parameters were obtained by LYSIS II software (Becton Dickinson, Mountain View, CA, USA).

\section{SDS-PAGE and immunoblotting}

Immunoblotting was done after separating the antigens in SDS-PAGE. Acrylamide $14 \%$ gels were used, following the method of Lugtenberg as previously described [30]. Samples were whole-cell lysates of $E$. coli (pAC2533), E. coli (pUC19), or Brucella strains, suspended at an $\mathrm{A}_{600}$ value of 5.0 (for Brucella suspensions) or 2.0 (for $E$. coli suspensions) in sample buffer, boiled for $10 \mathrm{~min}$, sonicated for $10 \mathrm{~s}$ and centrifuged. The supernates ( $30 \mu 1$ per lane) were then loaded. After electrophoresis, antigens in gels were electroblotted $\left(0.8 \mathrm{~mA} / \mathrm{cm}^{2}\right)$ for $1 \mathrm{~h}$. Nitrocellulose sheets were saturated (skimmed milk 3\%, Tween $0.05 \%$ PBS) for $1 \mathrm{~h}$ and incubated overnight with a pool of six immune sera from mice diluted 1 in 100 . All antibody dilutions were in skimmed milk $1 \%$, Tween $0.05 \%$ PBS if not otherwise indicated. Detection was by incubating blots successively in rabbit antimouse serum (Nordic, Tilburg, The Netherlands) diluted 1 in 500 and protein A-peroxidase (Sigma) diluted 1 in 2000 . The blots were developed in a solution containing $4.4 \mathrm{mM} \mathrm{H}_{2} \mathrm{O}_{2}$ and $\alpha$-chloronaphthol (Sigma) $0.5 \mathrm{mg} / \mathrm{ml}$. In some assays, pooled sera were first absorbed with a suspension of E. coli or Brucella cells. Adsorption was performed on sera diluted 1 in 100 in PBS, pH 7.2, with a 10:1 serum:packed cell volume ratio, by incubating once with agitation at room temperature for $2 \mathrm{~h}$. MAbs $\mathrm{A} 76 / 08 \mathrm{C} 03 / \mathrm{G} 03$ and A59/05F01/C09 were incubated together at a 1 in 500 dilution overnight and detected in the same conditions as indicated for immune sera.

\section{IFN- $\gamma$ determination}

IFN- $\gamma$ was determined in supernates of in-vitro restimulated splenocytes. Splenocytes were cultured in 24-well plates (Falcon, USA) at $2 \times 10^{6}$ cells $/ \mathrm{ml}$ in a total volume of $1.5 \mathrm{ml}$. Stimulating antigens were suspended in complete medium by sonication and distributed at $100 \mu 1$ well (equivalent to $10^{7}$ bacteria $/ \mathrm{ml}$ ). Cell culture supernates were harvested at $72 \mathrm{~h}$. IFN- $\gamma$ was determined by capture ELISA [32] in supernates pooled from duplicate wells (24-well culture plates). Immunocapture was achieved with purified anti-mouse IFN- $\gamma$ MAb (Pharmingen, USA) and detection was by incubating sequentially with rabbit (polyclonal) anti-murine IFN- $\gamma$ antibody (Immunegenex, USA) and alkaline phosphatase-conjugated goat anti-rabbit IgG $(\mathrm{H}+\mathrm{L})$ antibody (ICN, USA). Standard curves were constructed with murine recombinant IFN- $\gamma$ (Genzyme, USA). Cytokine concentrations in the samples were obtained by interpolating in the standard curve. Data from three determinations were analysed. 


\section{Mouse protection tests}

To evaluate the potential protective role of Omp25 expressed in E. coli against B. melitensis, mice (six per group) vaccinated with $E$. coli (pAC2533) and $E$. coli (pUC19) and control groups were challenged 45 days after the booster injection with four strains of $B$. melitensis differing in their mode of S-LPS expression (S B. melitensis H38, S B. melitensis 16M, S-R $B$. melitensis $\mathrm{EP}$ and $\mathrm{R}$ B. melitensis $\mathrm{B} 115$ ). The inocula were prepared from $24 \mathrm{~h}$ slants of each strain, and suspensions were adjusted taking an $\mathrm{A}_{600}$ value of 0.165 as equivalent to $10^{9}$ Brucella cells. Exact counts were determined retrospectively by plating on TSA. Mice were thus inoculated (i.v.) with $0.88 \times 10^{4} B$. melitensis $\mathrm{H} 38(\mathrm{~S}), 0.57 \times 10^{4}$ B. melitensis $16 \mathrm{M}(\mathrm{S})$, $4.5 \times 10^{7} B$. melitensis $\mathrm{EP}(\mathrm{S}-\mathrm{R})$ or $3.24 \times 10^{7} B$. melitensis $\mathrm{B} 115(\mathrm{R})$. At 15 days after infection, mice were killed by cervical dislocation and their spleens were removed aseptically, weighed and kept frozen $\left(-20^{\circ} \mathrm{C}\right)$ until further processing. For enumeration of $\mathrm{cfu} / \mathrm{spleen}$, the spleens were homogenised in stomacher bags, serially diluted and plated on TSA. Results were represented as the mean $\log$ cfu and SD per group.

\section{Statistical analysis}

Differences in spleen infection levels between the different groups were estimated through ANOVA by Fisher's protected least significant difference test (SuperANOVA software; Abacus Concepts, CA, USA).

\section{Results}

\section{Antibody responses}

Antibody reactivity and specificity. Antibodies to $B$. melitensis $\mathrm{H} 38(\mathrm{R})$ in sera of all mice immunised with $E$. coli (pAC2533) were detected as early as 15 days after infection, and peaked at 30-45 days (IgG titre = 7842) (Fig. 1). The booster further increased the antibody response ( $\operatorname{IgG}$ titre $=61520$ ), which peaked at around 60 days after infection. Sera from mice immunised with $E$. coli (pUC19) showed a much lower antibody reactivity to $B$. melitensis $\mathrm{H} 38$ (R) cells (mean IgG titres of 285 SD 57 and 845 SD 123 at 30 and 60 days after infection, respectively). Reactivity of immune sera to whole B. melitensis H38 (R) cells indicated the presence of antibodies to brucella surfaceexposed antigens. The specificity of antibodies was suggested by their higher binding activity in ELISA when sera against $E$. coli (pAC2533) were tested on $E$. coli (pAC2533) relative to E. coli (pUC19) cells (not shown).

Immunoblotting after SDS-PAGE was used to identify the molecules of $B$. melitensis reactive with anti- $E$. coli (pAC2533) immune sera. Antibodies of E. coli (pAC2533) immune sera reacted with a band at $25 \mathrm{kDa}$, corresponding to Omp25, on the five strains of B. melitensis tested (Fig. 2). This band was also

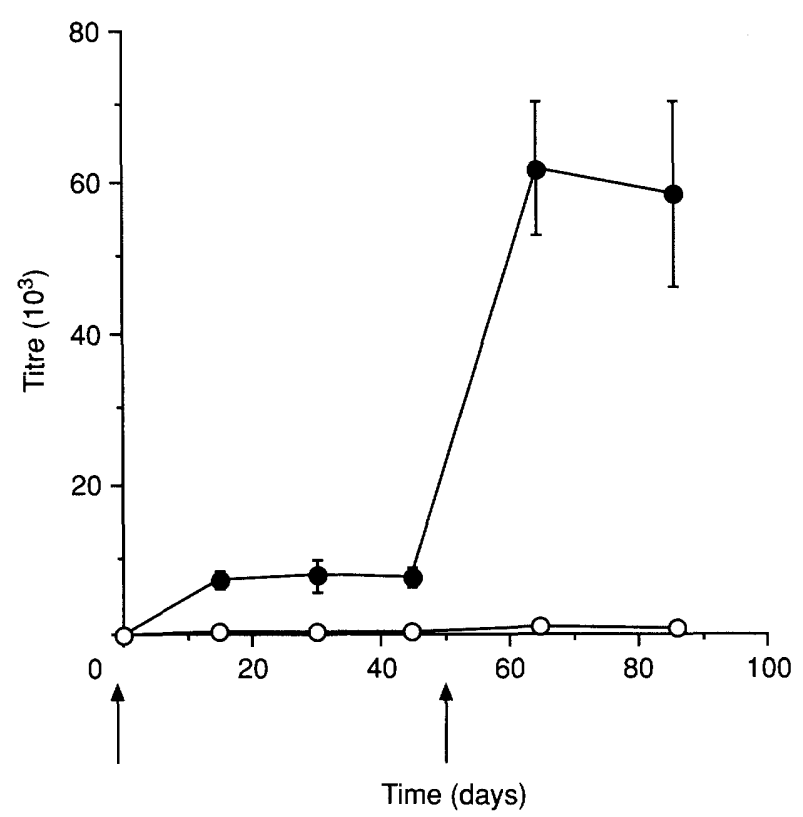

Fig. 1. Antibody response, measured by ELISA, to $B$. melitensis $\mathrm{H} 38(\mathrm{R})$ cells of mice immunised with $E$. coli (pAC2533) or $E$. coli (pUC19). Mice were first immunised i.v. at day 0 and boosted i.p. on day 52 with $E$. coli (pAC2533) (O) or E. coli (pUC19) (O) which express or do not express Omp25 of $B$. melitensis, respectively. Blood samples were taken at days 15,30 , 45,60 and 80 . Individual sera were tested in indirect ELISA for antibodies to $B$. melitensis $\mathrm{H} 38$ (R) whole cells. Plotted values represented the mean and SD $(n=6)$ of serum titres obtained by interpolating from logarithmic regression curves at an $\mathrm{A}_{600}$ value of 0.2 .

observed in the E. coli (pAC2533) lysate, but was absent from the $E$. coli (pUC19) lysate. In addition, among several faint bands, a second intense band was revealed in the $B$. melitensis lysates, which migrated between the 14-kDa and 20.1-kDa markers (Fig. 2) The origin of this additional band was then studied. For this, antibody reactivity in immunoblots of antiE. coli (pUC19) sera was analysed before and after adsorption with whole $B$. melitensis B115 cells (Fig. 3). Before adsorption, pooled sera detected many bands on $E$. coli lysates, among which was the additional band mentioned above (Fig. 2). This pool did not reveal Omp25 which was detected on the blot by anti-Omp25 MAb A59/05F01/C09. Adsorption of E. coli (pUC19) immune sera with B. melitensis B115 resulted in removal of antibodies tagging the additional band, which migrated to a position quite close to that of the $16.5-\mathrm{kDa}$ brucella OMP, as detected by MAb A76/08C03/G03. Furthermore, adsorption of $E$. coli (pAC2533) immune sera with E. coli (pUC19) cells also removed the cross-reacting antibodies and left $90 \%$ of the antibody binding on to $B$. melitensis H38 (R) whole-cells, as determined by indirect ELISA (data not shown).

These results indicated, first, that antibodies in sera of mice immunised with $E$. coli (pAC2533) recognised Omp25 of B. melitensis, and that a high proportion of 


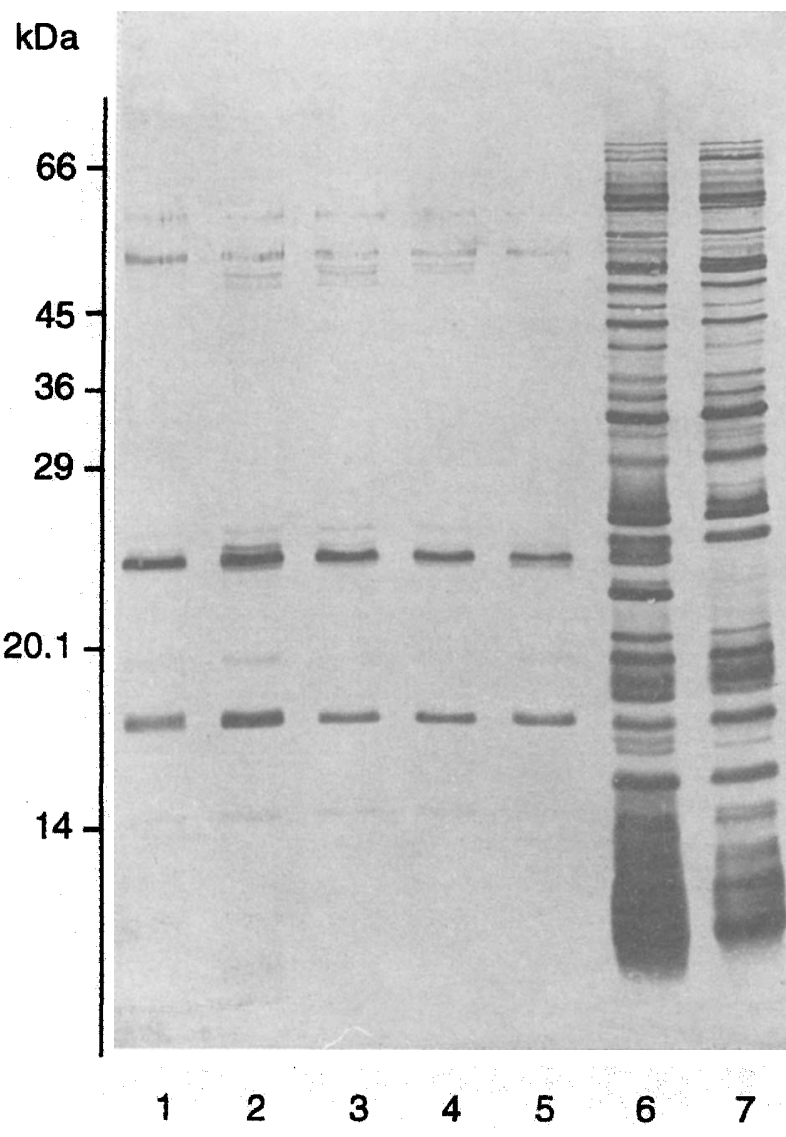

Fig. 2. Antibody reactivity of anti-E. coli (pAC2533) immune sera in immunoblotting. Whole-cell lysates of B. melitensis B115 (R) (lane 1); B. melitensis H38 (R) (2); B. melitensis EP (S-R) (3); B. melitensis H38 (S) (4); B. melitensis $16 \mathrm{M}(\mathrm{S})(5) ;$ E. coli (pAC2533) (6) and E. coli (pUC19) (7) were electrophoresed, blotted and incubated with a 1 in 100 dilution of pooled immune sera $(n=6)$. Molecular mass markers, positioned as indicated on the left, were: $14.2 \mathrm{kDa}, \alpha$-lactalbumin; $20.1 \mathrm{kDa}$, soybean trypsin inhibitor; $29 \mathrm{kDa}$, carbonic anhydrase; $36 \mathrm{kDa}$, glyceraldehyde 3 phosphate dehydrogenase; $45 \mathrm{kDa}$, ovalbumin; $66 \mathrm{kDa}$, bovine serum albumin.

the induced antibodies reacting with the $B$. melitensis cell surface were directed to this OMP and, second, that a proportion of the antibodies induced reacted with the denaturated protein in immunoblotting.

Influence of S-LPS on the binding of serum anti-Omp25 antibody to $B$. melitensis. The influence of the S-LPS of $B$. melitensis on the accessibility of Omp25 to specific antibodies was investigated. An indirect ELISA was devised which used suspensions of five $B$. melitensis strains for coating, all belonging to biovar 1 of $B$. melitensis, including S, S-R and R forms. The dilution curves indicated important differences in antibody binding (Fig. 4). The curves on $R$ and $S-R$ $B$. melitensis strains (B115 and $\mathrm{H} 38$ (R) and EP) plateaued (absorbances $\geqslant 3.0$ ) at c. 1 in 1000 dilution whereas those of S B. melitensis strains $16 \mathrm{M}$ and $\mathrm{H} 38$ (S) presented much lower absorbance values at that dilution, indicating a much better binding of antiOmp25 antibody on to B. melitensis $\mathrm{R}$ and $\mathrm{S}-\mathrm{R}$ than on

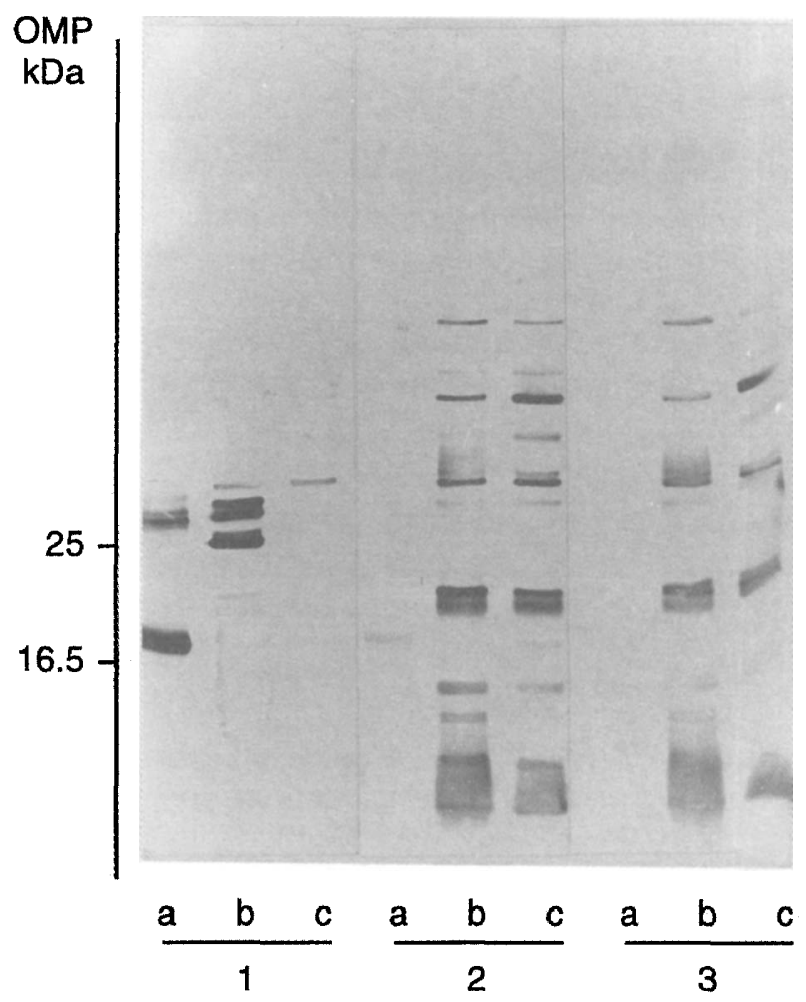

Fig. 3. Adsorption experiments with anti-E. coli immune sera. A pool $(\mathrm{n}=6)$ of anti-E. coli (pUC19) sera was reacted with electroblotted whole-cell lysates of $B$. melitensis H38 (R) (lanes a); E. coli (pAC2533) (b); E. coli (pUC19) (c). Nitrocellulose sheets were incubated with non-adsorbed anti-E. coli (pUC19) sera (1 in 100 dilution) (centre), or the same pool sera adsorbed with B. melitensis B115 (R) whole-cells (serum:cells ratio $=10: 1 \mathrm{v}: \mathrm{v})$ (right). As a control (left) blots were incubated with a mixture of two MAbs specific for the brucella 16.5-kDa OMP (MAb A76/08C03/G03) and brucella Omp25 (A59/05F01/C09).

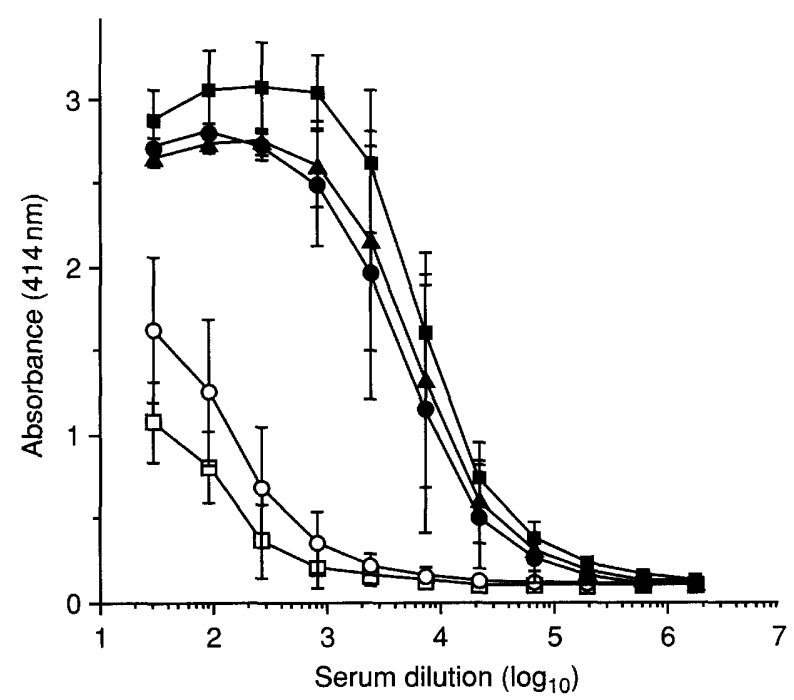

Fig. 4. Antibody reactivity to Omp 25 of E. coli (pAC2533) immune sera on to B. melitensis cells differing in their LPS expression. Immune sera were serially diluted and tested by whole-cell indirect ELISA on to $B$. melitensis $16 \mathrm{M}$ (S) ( $\square$ ), B. melitensis $\mathrm{H} 38$ (S) (O), B. melitensis $\mathrm{H} 38(\mathrm{R})(\mathbf{O}), B$. melitensis $\mathrm{EP}(\mathrm{S}-\mathrm{R})(\mathbf{\Delta})$, and $B$. melitensis B115 (R) (ם). Points represent the mean absorbance values and SD per groups of mice $(n=6)$. 
$B$. melitensis $\mathrm{S}$ strains. However, the binding on to $B$. melitensis $\mathrm{H} 38$ (S) was slightly higher than that on to B. melitensis $16 \mathrm{M}$.

Indirect ELISA with MAb A68/03F03/D05 specific for brucella R-LPS was used to control further the accessibility to epitopes located relatively deep in the surface of strains of $B$. melitensis. This MAb showed much better binding on to $\mathrm{R}$ and $\mathrm{S}-\mathrm{R}$ strains than on to $\mathrm{S} B$. melitensis strains $\mathrm{H} 38$ (S) and $16 \mathrm{M}$ (not shown). In addition, MAb A59/05F01/C09, specific for Omp25, showed a similar result (data not shown), comparable with that of binding of the polyclonal anti-Omp25 antibody.

Flow cytometry was used to monitor the binding of
anti-E. coli (pAC2533) sera antibodies to whole brucella cells in suspension. Brucella cells were incubated with an appropriate dilution of pooled immune sera $(n=6)$. The bacterial cell populations stained differently (Fig. 5); strains B115 (R), H38 (R) and EP (S-R) showed strong fluorescence signals (mean values: 714 SEM 10, 521 SEM 7 and 423 SEM 6 , respectively). In contrast, $\mathrm{S}$ strains $\mathrm{H} 38$ (S) and 16M (S) gave low values (71 SEM 3 and 83 SEM 4, respectively). Control suspensions gave consistently low values ( $<10$ fluorescence units). These results confirmed much better binding of anti-Omp25 antibodies on to individual cells of $\mathrm{R}$ and $\mathrm{S}-\mathrm{R}$ strains than on to $\mathrm{S}$ strains.

Taken together, these data strongly suggested that the
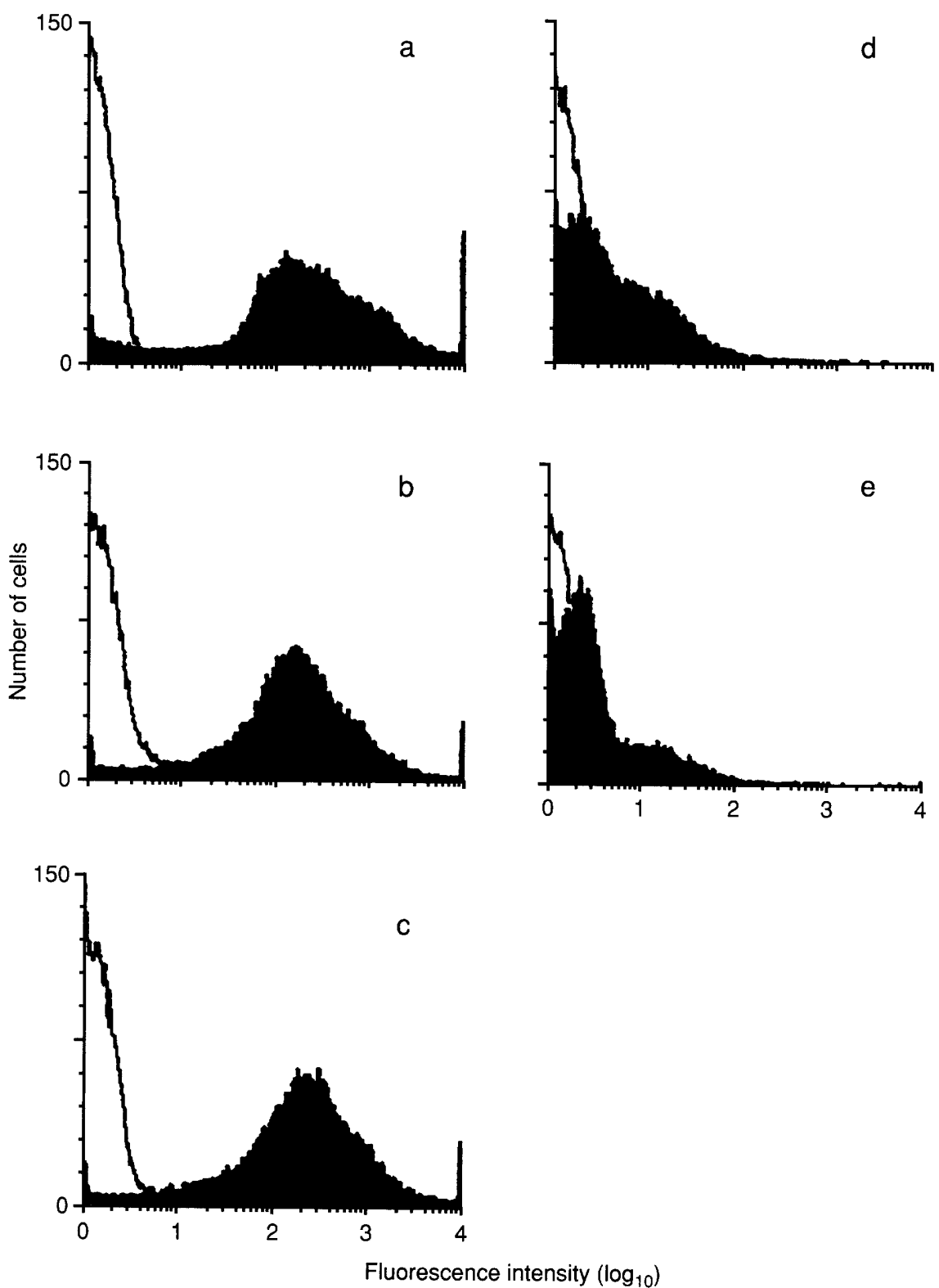

Fig. 5. Antibody reactivity, studied by flow cytometry, of E. coli (pAC2533) immune sera on to B. melitensis cells differing in their LPS expression. Suspensions of $B$. melitensis cells were successively incubated with anti-E. coli (pAC2533) pooled immune sera $(\mathrm{n}=6)$ diluted 1 in 300 and a FITC-goat anti-mouse IgG. Control cells were incubated with the FITC conjugate only. a, B. melitensis B115 (R); b, B. melitensis EP (S-R); c, B. melitensis H38 (R); d, B. melitensis $\mathrm{H} 38$ (S); e, B. melitensis 16M (S). 
accessibility of Omp25 to antibodies in E. coli (pAC2533) immune sera was greatly influenced by the S-LPS covering each of the $B$. melitensis strains tested.

Antibody isotypes. The antibody isotypes generated by immunisation with $E$. coli (pAC2533) and E. coli (pUC19) and reacting with $B$. melitensis $\mathrm{H} 38(\mathrm{R})$ cells were characterised. The results are shown in Table 1. Individual sera from mice immunised with $E$. coli (pAC2533) (taken before the time of challenge) showed a clear predominance of $\operatorname{IgG} 2 \mathrm{a}$ isotype in every case. The ratio of $\operatorname{IgG} 2 \mathrm{a}: \operatorname{IgG1}$ ranged between 1.41 and 9.53 . Mice were not uniform in their IgG1 and IgG2b antibody responses. Furthermore, IgG3 antibody levels were always the lowest. On the other hand, immunisation with $E$. coli (pUC19) was shown to provoke a mainly low titre IgM response similar to that observed with $E$. coli (pAC2533).

\section{IFN- $\gamma$ production}

IFN- $\gamma$ secretion from spleen cells was studied in vitro after re-stimulation. Splenocytes from both immunised and non-immunised mice prepared at the time of challenge were cultured with different antigens (Table $2)$. There were no significant differences $(p>0.05)$ between unstimulated cells from mice given either $E$. coli or saline. Cells from mice given E. coli (pA2533) or $E$. coli (pUC19) increased IFN- $\gamma$ secretion when stimulated with either $E$. coli $(\mathrm{pAC} 2533)(\mathrm{p}<0.001$ and $\mathrm{p}>0.05$, respectively) or $E$. coli (pUC19) $(\mathrm{p}<0.001$ and $\mathrm{p}<0.05$, respectively). On the contrary, cells from unimmunised (saline inoculated) mice were unable to increase their IFN- $\gamma$ production significantly upon re-stimulation $(\mathrm{p}<0.05)$.

\section{Protective activity}

The potential protective activity induced by $E$. coli (pAC2533) was evaluated by challenging mice with virulent and less virulent $B$. melitensis strains. The experiment was performed with the four $B$. melitensis strains which differed in their S-LPS expression.

Spleen weights of mice vaccinated with $E$. coli (pAC2533) and challenged with $B$. melitensis EP $(\mathrm{S}-\mathrm{R})$ and B115 (R) strains showed significant reduction $-p<0.05$ for EP (S-R) and $p<0.01$ for B115 (R) challenge - at 15 days after infection compared with groups immunised with $E$. coli (pUC19) or PBS controls (Table 3 ). No significant differences $(p>$ 0.05 ) were found in mice infected with the $S$ strains $\mathrm{H} 38$ (S) and 16M (S). Finally, no significant differences $(p>0.05)$ were detected between the two control groups - E. coli (pUC19) or PBS.

The splenic infection levels were also determined 15 days after infection (Table 2). Immunisation with $E$. coli (pAC2533) significantly reduced the number of brucella cfu compared with mice receiving PBS $(\mathrm{p}<0.01)$ or $E$. coli $(\mathrm{pUC19}) \quad(\mathrm{p}<0.05)$ when challenged with $R$ strain B115, S-R strain EP and $S$ strain H38 (S). No statistically significant differences $(p>0.05)$ were observed among the immunisation groups challenged with the $\mathrm{S}$ strain $16 \mathrm{M}$. Finally,

Table 1. Isotypes in immune sera of mice immunised with E. coli (pAC2533) expressing Omp25 of B. melitensis

\begin{tabular}{|c|c|c|c|c|c|c|}
\hline \multirow[b]{2}{*}{ Mouse no. } & \multicolumn{5}{|c|}{ Antibody titre* } & \multirow[b]{2}{*}{$\operatorname{IgG} 2 \mathrm{a} / \mathrm{G} 1$ ratio } \\
\hline & IgM & IgG1 & $\operatorname{IgG} 2 a$ & $\operatorname{IgG} 2 b$ & IgG3 & \\
\hline 1 & 905 & 203 & 6825 & 193 & 778 & 3.36 \\
\hline 2 & 950 & 2097 & 10121 & 1782 & 1192 & 4.82 \\
\hline 3 & 847 & 6967 & 9805 & 2801 & 1275 & 1.41 \\
\hline 4 & 882 & 1463 & 5133 & 2007 & 882 & 3.51 \\
\hline 5 & 856 & 2335 & 16887 & 2298 & 832 & 7.23 \\
\hline 6 & 1071 & 3139 & 29922 & 5764 & 2099 & 9.53 \\
\hline
\end{tabular}

*Antibody isotypes were determined by indirect ELISA on $B$. melitensis H38(R) whole cells.

Secondary antibodies were biotinylated anti-mouse isotypes.

Titres were calculated as the intercept from calculated slopes at $\mathrm{A}=0.2$.

Table 2. In-vitro IFN- $\gamma$ secretion from spleen cells of mice immunised with E. coli expressing brucella Omp25

\begin{tabular}{lcccc}
\hline & Mean (SEM) IFN- ${ }^{*}$ & & Secretion after immunisation with \\
\cline { 2 - 3 } \cline { 5 - 6 } Stimulating antigen & None (saline) & & E. coli (pAC2533) & E. coli (pUC19) \\
\hline E. coli (pAC2533) & $9.2(1.4)$ & $25.1(2.8)^{\dagger}$ & $12.9(5.0)$ \\
E. coli (pUC19) & $6.9(2.6)$ & $22.7(3.2)^{\dagger}$ & $14.6(4.2)^{\ddagger}$ \\
None (saline) & $7.1(2.9)$ & $2.9(1.7)$ & $6.3(1.6)$ \\
\hline
\end{tabular}

Unfractionated spleen cells $\left(2 \times 10^{6} / \mathrm{ml}\right)$ were cultured for $72 \mathrm{~h}$ in the presence or absence of sonicated $E$. coli cells (equivalent to $\mathrm{A}_{600}=0.1$ ). Supernates were then assayed for IFN- $\gamma$ by a capture ELISA.

* $(\mathrm{ng} / \mathrm{ml})$.

${ }^{\dagger} \mathrm{p}<0.001$.

$\ddagger_{p}<0.05$. 
Table 3. Evaluation of protection induced by E. coli (pAC2533) in BALB/c mice

\begin{tabular}{|c|c|c|c|c|c|}
\hline \multirow[b]{2}{*}{ Vaccine } & & \multicolumn{4}{|c|}{ 1. Mean (SD) cfu/spleen* and 2. spleen weight $(\mathrm{g})$ with $B$. melitensis challenge strain } \\
\hline & & B115 & EP & H38 (S) & $16 \mathrm{M}$ \\
\hline \multirow[t]{2}{*}{ E. coli $(\mathrm{pAC} 2533)$} & 1. & $6.41(0.18)^{\dagger}$ & $5.10(0.55)^{\dagger}$ & $5.61 \quad(0.33)^{\dagger}$ & $\begin{array}{ll}4.63 \quad(0.72) \\
\end{array}$ \\
\hline & 2. & $0.269(0.033)$ & $0.360(0.062)$ & $0.230(0.028)$ & $0.285(0.050)$ \\
\hline \multirow{2}{*}{ E. coli (pUC19) } & 1. & $6.78 \quad(0.28)^{\frac{7}{4}}$ & $5.70 \quad(0.27)^{f}$ & $6.31(0.21)^{f}$ & $4.98(0.58)^{+}$ \\
\hline & 2. & $0.371(0.037)$ & $0.448(0.038)$ & $0.277(0.086)$ & $0.287(0.034)$ \\
\hline \multirow{2}{*}{ PBS } & 1. & $7.06 \quad(0.20)$ & $6.15(0.25)$ & $6.18 \quad(0.56)$ & $4.78(0.13)$ \\
\hline & 2. & $0.402(0.058)$ & $0.456(0.063)$ & $0.235(0.120)$ & $0.289(0.031)$ \\
\hline
\end{tabular}

Mice vaccinated with $E$. coli (pAC2533) and $E$. coli (pUC19) expressing or not expressing, respectively the Omp25 of $B$. melitensis were infected intravenously 45 days after the booster injection. Controls received PBS. Exact doses injected were: $0.88 \times 10^{4}$ B. melitensis $\mathrm{H} 38$ (S); $0.57 \times 10^{4}$ B. melitensis $16 \mathrm{M}(\mathrm{S}) ; 4.5 \times 10^{7}$ B. melitensis $\mathrm{EP}(\mathrm{S}-\mathrm{R})$ or $3.24 \times 10^{7}$ B. melitensis $\mathrm{B} 115(\mathrm{R})$. Mice were killed 15 days after infection and the level of spleen infection was determined.

${ }^{*}$ Groups of six mice.

${ }^{\dagger}$ Different (Fisher's PLSD test) $(\mathrm{p}<0.05)$ from E. coli $(\mathrm{pUC19)}$ vaccinated group and from controls inoculated with PBS.

${ }^{\ddagger}$ Not statistically different from PBS-injected mice.

immunisation with E. coli (pUC19) did not diminish the number of cfu $(\mathrm{p}>0.05)$ compared with controls receiving $\mathrm{PBS}$.

\section{Discussion}

The immunogenicity and active protection against $B$. melitensis induced in mice by $E$. coli expressing the major Omp25 of B. melitensis was evaluated. This construct provided firstly the Omp25 free of other brucella antigens and, secondly, an outer-membrane framework beneficial for appropriate folding and exposure of the protein [28].

Whole-cell sonicates of E. coli (pAC2533) cells expressing the omp 25 gene of $B$. melitensis $16 \mathrm{M}$ were used to obtain a high antibody response to Omp25 in mice without the addition of extrinsic adjuvants. Antibodies reacted at high titre on to $B$. melitensis $\mathrm{H} 38(\mathrm{R})$. Immunoblotting revealed Omp25 and another band found to be a cross-reactive surface antigen, probably brucella $16.5-\mathrm{kDa}$ OMP which shows sequence homology to E. coli peptidoglycanassociated lipoprotein (PAL) [33]. Furthermore, ELISA and immunoblotting showed that there were probably antibodies to both non-denaturated, surface-exposed protein and to denaturated protein, most likely representing conformational and linear epitopes, respectively $[28,34,35]$. The amount of antigen injected could have contributed to the strong response to Omp25. When Salmonella was used as expression vector for a plasmid-encoded antigen, it was observed that the initial amount of antigen priming the immune system had more impact than the persistence of the vector strain in the mouse tissues [36].

On the basis of earlier reports [37], both the i.v. and i.p. routes were used for immunisation. This has been shown to favour the production of antibodies to conformational, exposed protein epitopes [37], which was of interest in the present model. As other routes were not compared, it is not possible to deduce whether this accounted for the type of response obtained. However, insertion of OMPs into bilayer membranes could have important consequences for the quality of antibody responses obtained. For instance, when inserted into liposomes, the Por protein of the gonococcus induced a greater proportion of antibodies able to bind to whole neisseria cells than when injected as proteosomes or as an alum-adsorbed preparation [38]. Moreover, a porin from Salmonella has been shown to induce higher protection in mice when associated with LPS; this effect was even stronger than when monophosphoryl lipid A, the moiety of LPS with adjuvant activity, was used [39]. Class 1 OMP from Neisseria meningitidis produced in Bacillus subtilis and purified under denaturating conditions was shown to refold adequately when complexed with salmonella LPS [40]; furthermore, antisera prepared with LPS-associated OMP induced bactericidal and protective antibodies in contrast to unfolded protein [40]. This supported the idea that LPS had a role in the conformation, and hence the presentation of OMPs to the immune system. In addition, it has been shown that purified brucella OMPs were capable of integrating into lipid bilayers of heterologous LPS preparations [41] and multilayers of brucella R-LPS [35]; the latter was also shown to restore antigenicity. The results of the present study are consistent, in that higher responses to Omp25 on whole brucella cells were obtained when immunising with membrane-associated Omp25 instead of a recombinant, purified fusion Omp25 (unpublished results). This could be due to a bias in antibody specificity of immune sera to epitopes located deeper in Omp25, as above, or to a loss of tertiary structure (antigenicity) of the cytoplasm-derived constructs compared to the properly folded, membrane-associated protein, or both.

Mice immunised with E. coli (pAC2533) showed a limited but significant reduction in splenic infection levels when challenged with R B115, S-R EP and S H38 strains, but not with strain $16 \mathrm{M}$. The amount of S-LPS expressed by these strains greatly influenced 
the binding of polyclonal antibodies specific for Omp25. The results agreed with previous data that showed greater accessibility of OMP epitopes - as well as of core LPS - to MAbs in R strains of several Brucella spp. [21, 22, 24, 25]. The difference in protective activity observed against the two $\mathrm{S}$ strains could probably be linked with the relatively higher binding of anti-Omp25 antibodies on B. melitensis $\mathrm{H} 38$ (S) than on $B$. melitensis $16 \mathrm{M}$. However, yet unexplored in-vivo modifications of the expression of outer-membrane antigens could also account for different antibody activity. Alternatively, this might have reflected intrinsic virulence differences between strains. Although small, protection obtained with $E$. coli (pAC2533) was greater than that reported with killed whole-cell rough brucella vaccines against $B$. melitensis and B. suis [42].

It is as yet premature to speculate about the mechanisms responsible for the protection observed. Macrophages could have been activated by IFN- $\gamma$, becoming more bactericidal [43, 44]. However, this sole mechanism could not explain the reduction in splenic infection, as high IFN- $\gamma$ secretion was found with cells from mice immunised with both $E$. coli (pAC2533) and E. coli (pUC19). Adjuvants may affect both specificity and isotype of antibody responses [45]. So, E. coli LPS could have modulated the antibody switching by favouring IgG2a over the other isotypes. LPS is recognised as a powerful inducer of tumour necrosis factor and IFN- $\gamma$, and the latter has been shown to drive B cells to IgG2a synthesis [46]. Therefore, IgG2a antibodies could have bound brucella cells through Omp25 mediating opsonic phagocytosis or complement killing [47]; an earlier study has already shown that IgG2a MAbs against OMPs, including anti-Omp25 MAbs, protect mice against $B$. ovis [48]. Experiments including passive transfer of immune sera and cells to mice as well as in-vitro testing for bacteriolysis and opsonophagocytic killing should be done to clarify these points.

Few protection trials have been reported concerning recombinant Brucella proteins. Fusion BaOMP were tested in lymphocyte proliferation tests on B. abortusinfected cattle [49]. However, neither antibody nor protection tests were considered. A recombinant salmonella expressing a soluble $B$. abortus protein (BCSP-31) was tested in mice [50, 51] and swine [51], but no protective activity was registered. Protection was demonstrated against $B$. abortus by immunising mice with a peptide derived from the sequence of the $B$. abortus $\mathrm{Cu}-\mathrm{Zn}$ superoxide-dismutase; however, the whole recombinant protein was not efficacious [52]. More recently a purified recombinant ribosomal protein was shown to be protective in mice, inducing both immune cells and antibodies [53]. This would indicate that immune (protective) mechanisms against brucella might involve both internal and outer-membrane antigens.
This is the first report on immunogenicity and protective activity of an $E$. coli-expressed recombinant OMP of brucella. Although the protection reported here with Omp25 was limited, the approach is promising for the evaluation of other brucella OMPs, especially where conservation of folding is critical. Work is in progress to examine further the immune responses to Omp25 and other recombinant brucella proteins and to evaluate them as protective antigens against smooth and rough Brucella strains.

We thank D. Buzoni-Gatel, S. Bernard, T. Chardès and M. Olivier for helpful advice. We also thank H. Leroux, E. Rabouan and P. Lechopier (animal housing facility). A.C. received a post-doctoral fellowship from C.E.C. R.A.B. thanks INRA and Facultad de Ciencias Veterinarias, UNICEN, Argentina, for support. This work was in part supported by C.E.C. contract Eclair AGRE-CT90-0049-C.

\section{References}

1. Adams LG. Development of live Brucella vaccines. In: Adams LG (ed) Advances in brucellosis research. College Station, Texas A \& M University Press. TX, 1990: 250-276.

2. Plommet $M$. Killed vaccines in cattle: current situation and perspectives. In: Adams LG (ed) Advances in brucellosis research. College Station, Texas A \& M University Press. TX, 1990: 215-227.

3. Dubray G, Bézard G. Isolation of three Brucella abortus cellwall antigens protective in murine experimental brucellosis. Ann Rech Vet 1980; 11: 367-373.

4. Dubray G, Charriaut C. Evidence of three major polypeptide species and two major polysaccharide species in the Brucella outer membrane. Ann Rech Vet 1983; 14: 311-318.

5. Dubray G. Protective antigens in brucellosis. Ann Inst Pasteur Microbiol 1987; 138: 84-87.

6. Jiménez de Bagüés MP, Elzer PH, Blasco JM, Marín CM, Gamazo C, Winter AJ. Protective immunity to Brucella ovis in $\mathrm{BALB} / \mathrm{c}$ mice following recovery from primary infection or immunization with subcellular vaccines. Infect Immun 1994; 62: $632-638$.

7. Winter AJ, Rowe GE. Comparative immune responses to native cell envelope antigens and the hot sodium dodecyl sulfate insoluble fraction (PG) of Brucella abortus in cattle and mice. Vet Immunol Immunopathol 1988; 18: 149-163.

8. Robinson A, Melling J. Envelope structure and the development of new vaccines. J Appl Bacteriol 1993; 74 Suppl: 43S$51 \mathrm{~S}$

9. Cloeckaert A, Jacques I, Limet JN, Dubray G. Immunogenic properties of Brucella melitensis cell-wall fractions in BALB/c mice. J Med Microbiol 1995; 42: 200-208.

10. Sowa BA, Kelly KA, Ficht TA, Frey M, Adams LG. SDSsoluble and peptidoglycan-bound proteins in the outer membrane-peptidoglycan complex of Brucella abortus. Vet Microbiol 1991; 27: 351-369.

11. Gamazo C, Winter AJ, Moriyón I, Riezu-Boj JI, Blasco JM, Díaz R. Comparative analyses of proteins extracted by hot saline or released spontaneously into outer membrane blebs from field strains of Brucella ovis and Brucella melitensis. Infect Immun 1989; 57: 1419-1426.

12. Cloeckaert A, Zygmunt MS, de Wergifosse P, Dubray G, Limet JN. Demonstration of peptidoglycan-associated Brucella outermembrane proteins by use of monoclonal antibodies. $J$ Gen Microbiol 1992; 138: 1543-1550.

13. Verstreate DR, Creasy MT, Caveney NT, Baldwin CL, Blab MW, Winter AJ. Outer membrane proteins of Brucella abortus: isolation and characterization. Infect Immun 1982; 35: 979-989.

14. Cherwonogrodzky JW, Dubray G, Moreno E, Mayer $\mathrm{H}$. Antigens of Brucella. In: Nielsen K, Duncan JR (eds) Anima brucellosis. Boca Ratón, CRC Press. 1990: 19-64.

15. Moriyón I, Gamazo C, Díaz R. Properties of the outer membrane of Brucella. Ann Inst Pasteur Microbiol 1987; 138: 89-91. 
16. Cloeckaert A, Jacques I, de Wergifosse P, Dubray G, Limet JN. Protection against Brucella melitensis or Brucella abortus in mice with immunoglobulin $\mathrm{G}$ (IgG), IgA and $\operatorname{IgM}$ monoclonal antibodies specific for a common epitope shared by the Brucella $\mathrm{A}$ and $\mathrm{M}$ smooth lipopolysaccharides. Infect Immun 1992; 60: 312-315.

17. Limet J, Plommet AM, Dubray G, Plommet M. Immunity conferred upon mice by anti-LPS monoclonal antibodies in murine brucellosis. Ann Inst Pasteur Immunol 1987; 138: $417-424$.

18. Limet JN, Bosseray N, Garin-Bastuji B, Dubray G, Plommet M. Humoral immunity in mice mediated by monoclonal antibodies directed against the $\mathrm{A}$ and $\mathrm{M}$ antigens of Brucella. $J$ Med Microbiol 1989; 30: 37-43.

19. Montaraz JA, Winter AJ, Hunter DM, Sowa BA, Wu AM, Adams LG. Protection against Brucella abortus in mice with O-polysaccharide-specific monoclonal antibodies. Infect Immun 1986; 51: $961-963$.

20. Phillips M, Deyoe B, Canning PC. Protection of mice against Brucella abortus infection by inoculation with monoclonal antibodies recognizing Brucella O-antigen. Am J Vet Res 1989; 50: $2158-2161$

21. Cloeckaert A, Jacques I, Bosseray N et al. Protection conferred on mice by monoclonal antibodies directed against outermembrane-protein antigens of Brucella. $J$ Med Microbiol 1991; 34: 175-180.

22. Cloeckaert A, Jacques I, Bowden RA, Dubray G, Limet JN. Monoclonal antibodies to Brucella rough lipopolysaccharide: characterization and evaluation of their protective effect against $B$. abortus. Res Microbiol 1993; 144: 475-484.

23. Jacques I, Cloeckaert A, Limet JN, Dubray G. Protection conferred on mice by combinations of monoclonal antibodies directed against outer-membrane proteins or smooth lipopolysaccharide of Brucella. $J$ Med Microbiol 1992; 37: 100-103.

24. Bowden RA, Cloeckaert A, Zygmunt MS, Bernard S, Dubray G. Surface exposure of outer membrane protein and lipopolysaccharide epitopes in Brucella species studied by enzymelinked immunosorbent assay and flow cytometry. Infect Immun 1995; 63: 3945-3952.

25. Cloeckaert A, de Wergifosse P, Dubray G, Limet JN. Identification of seven surface-exposed Brucella outer membrane proteins by use of monoclonal antibodies: immunogold labeling for electron microscopy and enzyme-linked immunosorbent assay. Infect Immun 1990; 58: 3980-3987.

26. de Wergifosse $P$, Lintermans $P$, Limet $\mathrm{N}$, Cloeckaert A. Cloning and nucleotide sequence of the gene cloding for the major 25-kilodalton outer membrane protein of Brucella abortus. J Bacteriol 1995; 177: 1911-1914.

27. Cloeckaert A, Verger J-M, Grayon M, Grépinet O. Restriction site polymorphism of the genes encoding the major $25 \mathrm{kDa}$ and $36 \mathrm{kDa}$ outer-membrane proteins of Brucella. Microbiology 1995; 141: 2111-2121.

28. Cloeckaert A, Verger J-M, Grayon M, Zygmunt MS, Grépinet O. Nucleotide sequence and expression of the gene encoding the major 25-kilodalton outer membrane protein of Brucella ovis: evidence for antigenic shift, compared with other Brucella species, due to a deletion in the gene. Infect Immun 1996; 64: 2047-2055.

29. Alton GG, Jones LM, Angus RD, Verger JM. Techniques for the brucellosis laboratory. Paris, Institut National de la Recherche Agronomique. 1988.

30. Bowden RA, Verger JM, Grayon M, Limet JN, Dubray G. Simultaneous expression of smooth and rough phase properties related to lipopolysaccharide in a strain of Brucella melitensis. J Med Microbiol 1993; 39: 363-370.

31. Cloeckaert A, Zygmunt MS, Nicolle J-C, Dubray G, Limet JN. O-chain expression in the rough Brucella melitensis strain B115: induction of O-polysaccharide-specific monoclonal antibodies and intracellular localization demonstrated by immunoelectron microscopy. J Gen Microbiol 1992; 138: 1211-1219.

32. Mossman TR, Fong TAT. Specific assays for cytokine production by $\mathrm{T}$ cells. $J$ Immunol Methods 1989; 116: $151-158$.

33. Tibor A, Weynants V, Denoel $\mathrm{P}$ et al. Molecular cloning, nucleotide sequence, and occurrence of a 16.5 kilodalton outer membrane protein of Brucella abortus with similarity to PAL lipoproteins. Infect Immun 1994; 62: 3633-3639.

34. Berzofsky JA, Berkower IJ. Immunogenicity and antigen structure. In: Paul WE (ed) Fundamental immunology, 2nd edn. New York, Raven Press. 1989: 169-208.

35. Cloeckaert A, Zygmunt MS, Bézard G, Dubray G. Purification and antigenic analysis of the major 25-kilodalton outer membrane protein of Brucella abortus. Res Microbiol 1996; 147: $225-235$.

36. Cárdenas L, Clements JD. Stability, immunogenicity and expression of foreign antigens in bacterial vaccine vectors. Vaccine 1993; 11: 126-135.

37. Leclerc C, Charbit A, Molla A, Hofnung M. Antibody response to a foreign epitope expressed at the surface of recombinant bacteria: importance of the route of immunization. Vaccine 1989; 7: 242-248.

38. Wetzler LM, Blake MS, Barry K, Gotschlich EC. Gonococcal porin vaccine evaluation: comparison of por proteosomes, liposomes, and blebs isolated from rmp deletion mutants. $J$ Infect Dis 1992; 166: 551-555.

39. Muthukkumar S, Muthukkaruppan VR. Mechanism of protective immunity induced by porin-lipopolysaccharide against murine salmonellosis. Infect Immun 1993; 61: 3017-3025.

40. Nurminen $M$, Butcher $S$, Idänpään-Heikkilä I et al. The class 1 outer membrane protein of Neisseria meningitidis produced in Bacillus subtilis can give rise to protective immunity. Mol Microbiol 1992; 6: 2499-2506.

41. Moriyón I, Montañés MA. In vitro interactions between lipopolysaccharides and heterologous outer membrane porin proteins. Curr Microbiol 1985; 12: 229-234.

42. Winter AJ, Schurig GG, Boyle SM et al. Protection of BALB/c mice against homologous and heterologous species of Brucella by rough strain vaccines derived from Brucella melitensis and Brucella suis biovar 4. Am J Vet Res 1996; 57: $677-683$.

43. Jones SM, Winter AJ. Survival of virulent and attenuated strains of Brucella abortus in normal and gamma interferonactivated murine peritoneal macrophages. Infect Immun 1992; 60: $3011-3014$.

44. Zhan Y, Cheers C. Endogenous gamma interferon mediates resistance to Brucella abortus infection. Infect Immun 1993; 61: $4899-4901$.

45. ten Hagen TLM, Sulzer AJ, Kidd MR, Lal AA, Hunter RL. Role of adjuvants in the modulation of antibody isotype, specificity, and induction of protection by whole blood-stage Plasmodium yoelii vaccines. J Immunol 1993; 151: 7077-7085.

46. Finkelman FD, Katona IM, Mosmann TR, Coffman RL. IFN- $\gamma$ regulates the isotype of $\mathrm{Ig}$ secreted during in vivo humoral immune responses. J Immunol 1988; 140: 1022-1027.

47. Potter M. Immunoglobulins and immunoglobulin genes. In: Foster HL, Small JD, Fox J (eds) Mouse in biomedical research, vol 2. New York, Academic Press. 1984: 347-380.

48. Bowden RA, Cloeckaert A, Zygmunt MS, Dubray G. Outermembrane protein- and rough lipopolysaccharide-specific monoclonal antibodies protect mice against Brucella ovis. $J$ Med Microbiol 1995; 43: 344-347.

49. Smith R, Adams LG, Ficht TA, Sowa BA, Wu A. Immunogenicity of subcellular fractions of Brucella abortus: measurement by in vitro lymphocyte proliferative responses. Vet Immunol Immunopathol 1990; 25: 83-97.

50. Stabel TJ, Mayfield JE, Tabatabai LB, Wannemuehler MJ. Oral immunization of mice with an attenuated Salmonella typhimurium containing a recombinant plasmid which codes for production of a 31-kilodalton protein of Brucella abortus. Infect Immun 1990; 58: 2048-2055.

51. Stabel TJ, Mayfield JE, Morfitt DC, Wannemuehler MJ. Oral immunization of mice and swine with an attenuated Salmonella choleraesuis [ $\Delta$ cya- $12 \Delta$ (crp-cdt)19] mutant containing a recombinant plasmid. Infect Immun 1993; 61: 610-618.

52. Tabatabai LB, Pugh GW. Modulation of immune responses in Balb/c mice vaccinated with Brucella abortus $\mathrm{Cu}-\mathrm{Zn}$ superoxide dismutase synthetic peptide vaccine. Vaccine 1994; 12: 919-924.

53. Oliveira SC, Splitter GA. Immunization of mice with recombinant $\mathrm{L} 7 / \mathrm{L} 12$ ribosomal protein confers protection against Brucella abortus infection. Vaccine 1996; 14: 959-962. 